\title{
Article
}

\section{Retrospective study of parasitic diseases of cattle through laboratory analysis of clinical samples at Bangladesh Livestock Research Institute, Regional Station, Baghabari, Sirajganj, Bangladesh}

\author{
Md. Humayun Kabir ${ }^{1 *}$, Md. Ershaduzzaman ${ }^{2}$, Mohammed Sirajul Islam ${ }^{1}$, Seikh Masudur Rahman, ${ }^{1}$ Md. Rezaul \\ Karim $^{3}$, Md. Zakir Hasan ${ }^{3}$, Md. Abu Haris Miah ${ }^{1}$, Md. Yousuf Ali ${ }^{1}$, Shafaat Mahjabun ${ }^{4}$, Sumona Aktar ${ }^{5}$ and \\ Md. Shahjahan ${ }^{1}$ \\ ${ }^{1}$ Bangladesh Livestock Research Institute, Regional Station, Baghabari, Sirajganj, Bangladesh \\ ${ }^{2}$ System Research Division, Bangladesh Livestock Research Institute, Savar, Dhaka, Bangladesh \\ ${ }^{3}$ Animal Health Research Division, Bangladesh Livestock Research Institute, Savar, Dhaka, Bangladesh \\ ${ }^{4}$ Rangpur Medical College and Hospital, Rangpur, Bangladesh \\ ${ }^{5}$ Central Dairy Farm and Cattle Breeding Station, Savar, Dhaka, Bangladesh
}

*Corresponding author: Md. Humayun Kabir, Bangladesh Livestock Research Institute, Regional Station, Baghabari, Sirajganj, Bangladesh. E-mail: hkabirvet@yahoo.com

Received: 06 December 2018/Accepted: 26 December 2018/ Published: 30 December 2018

\begin{abstract}
Cattle are affected by different types of parasitic diseases that can lead to economic losses to the farmers in terms of reduced growth and production performance and increased mortality. As such, this study was conducted at Animal Health Laboratory of BLRI regional station, Baghabari, Sirajganj to determine the clinical prevalence of various types of parasitic diseases in cattle of different age groups, sexes and seasons of a year. The data were collected during the period of July 2016 to June 2017 from the record book of AHL. Diagnosis of each faeces sample was done by direct observation, indirect smear and sedimentation method for the diagnosis of whole parasites, ova, larvae and cyst of enteric parasites. The total number of faeces sample was 701. It was observed that parasitic infestation was not affected by various body weight $(p>0.05)$ but the age variation had significant differences $(\mathrm{p}<0.05)$ in infestation level. According to various parasitic loads multiple infestation observed $(p<0.05)$ in those cattle having higher body weight. However, single infestation (Ascaria) identified in lower body weight (calf). In the Summer, single infestation found higher (44\%) followed by double (32\%) and non-infestation (17\%). Similar patterns observed in Rainy, Autumn and Winter seasons of the studied feces samples. These data indicated higher percentage of single infestation in the tested samples followed by double parasitic loads. In addition, single infestation was higher in Autumn (54\%) and Winter (59\%) season while double parasitic loads found frequently in Summer (32\%) and Rainy (37\%) seasons. The frequency of Fasciola (21\%) was observed the most followed by Fasciola + Paramphiastomum (13\%) and Balantidium coli $(10 \%)$ in the Summer. The frequency of Fasciola and Balantidium coli identified in similar pattern during Rainy, Autumn and Winter seasons. These data suggested that proper measure should be taken for those specific parasitic infestations in those areas from where feces samples were tested. In the tested feces samples of male and female $15.2 \%$ and $17.5 \%$ were found for Fasciola in both followed by Balantidium coli, respectively, $15.2 \%$ and $14.9 \%$ (Table 5). In case of double infestation of Fasciola \& Paramphiastomum and Fasciola \& Balantidium coli were $12.3 \%$ \& $12.7 \%$ and $7.4 \%$ and $7.0 \%$, respectively. This study will be conducted every year from now on and these large set of data can act as a guideline for farther research activities with parasitic diseases eradication and control of the surrounding areas of Baghabari.
\end{abstract}

Keywords: cattle; parasitic diseases; prevalence; season; sex; age 


\section{Introduction}

There are about 240.86 lakh cattle in Bangladesh (DLS, 2018). These animals are important for good quality meat, milk, leathers and a source of income to farmers. Livestock is an integrated part of our farming system and plays an important role in the traditional economy of Bangladesh. Disease problems especially related to internal parasites represent a serious threat, which has been hindering the cattle development in Bangladesh for long time (Islam et al., 2015). The losses of productivity of animal in terms of mortality, reduced milk and meat, and loss of reproduction rate due to parasitism were to the extent of 50\% in Bangladesh (ADB 1984). Therefore, it is necessary to know the type of parasites causing infection and losses in cattle industry for developing effective treatment, prevention and control measures. Climatic condition of Bangladesh is highly favourable for survival, development and reproduction of different parasites and the temperature, humidity and rainfall of the country are highly fevourable for parasites (Sarker et al., 2015). For this reason the present study has been undertaken in Animal Health Laboratory, Bangladesh Livestock Research Institute, Regional Station, Baghabari, Sirajganj with the following objectives: to find out the prevalence and seasonal variation of various flukes and gastro-intestinal parasite infections in native and crossbred cattle. This paper describes the important clinical problems of cattle at Baghabari Milking zone of Bangladesh.

\section{Materials and Methods}

\subsection{Study area and period of study}

To have a retrospective study of the gastro-intestinal parasitic infection in cattle, the samples were received from different area around Sahajadpur upazilla of Sirajgong district namely Bara, Faridpur, Demra, Bahangura of Pubna and Ullapara, Belkuchi, Chouhali, Kamarkhanda of Sirajgong. The study was conducted during the period from July 2016 to June 2017.

\subsection{Climatic conditions of the study areas}

The climatic conditions of the selected study areas were more or less similar to the average condition of the country. The climate of Pubna and Sirajgong district are moderate in nature. The maximum temperature is $37^{\circ} \mathrm{C}$ in May followed by a minimum temperature of $15^{\circ} \mathrm{C}$ in January. The rainfall is moderate in respect of other areas of Bangladesh.

\subsection{Collection of fecal samples}

Fecal samples were collected by the farmers directly from the rectum of each animal or from the pasture immediately after defecation and was transported to the AHL of BLRI-RS, Baghabari. About 10-15gm of fecal samples was collected. After collection, the samples were kept on the refrigerator and bring to the laboratory for further processing. All fecal samples were collected in separate cups. To prevent potential cross contamination between fecal samples, separate disposable gloves were worn for each collected sample. Fecal samples collected in the field were kept refrigerated at $4^{\circ} \mathrm{C}$ until processed for further examination.

\subsection{Examination and identification of parasites}

After collection, the samples were immediately carried out to the laboratory and examined by direct smear method and sedimentation method to detect ova or larva of nematodes according to Soulsby18. Direct smear method A thin smear was prepared by spreading a small amount of feces in a grease free clean slide and then examined under microscope with low power objectives of 10X described by Soulsby 18.

\subsection{Sedimentation method}

In this method, about 5-10 gm feces were mixed with $50-100 \mathrm{ml}$ of water in cylinder and were allowed to sediment for 15-20 minutes. The supernatant was carefully discarded without disturbing the sediment. Finally smear was made with a small amount of the sediment on a grease free glass slide and was examined using $10 \mathrm{X}$ eye-piece and 10X object. Some samples were considered negative after examination of three slides with no eggs or larvae segment were identified on the basis of morphological characteristics described by Soulsby (1982).

\subsection{Ethics statement}

The handling of animals in the study well be performed in accordance with the current Bangladesh legislation (Cruelty to Animals Act 1920, Act No. I of 1920 of the Government of the People's Republic of Bangladesh). The specific experiments was approved by the Ethics Committee of the Bangladesh Livestock Research Institute, Saver, Dhaka. 


\subsection{Data analysis}

Collected data were tabulated and analyzed by statistical software SPSS var.17 for descriptive statistics such as average, percentage etc.

\section{Results and Discussion}

This study revealed that the overall prevalence of gastro-intestinal parasites is much higher in crossbred cattle (71\%) than that of native breed (41\%) except Strongylid. The rate was almost similar in native and crossbred cattle in respect of Strongyloids. This finding was in line with the study of Ross et al. (1959) and Sardar et al. (2006) and Rahman et al. (1983) who reported that the Bos indicus are more resistant to parasites than Bos taurus. Haque (1986) also reported that the gastro-intestinal parasitic infestation rate was higher in crossbred cattle.

The age and body weight-wise prevalence rate of different gastro-intestinal parasites of cattle are presented in Table 1. Different parasitic load based on body weight $(p<0.05)$ and age $(p<0.001)$ showed significant differences in the studied cattle population. The body weight of cattle ranged 172 to $225 \mathrm{~kg}$ affected by different type of parasites. According to various parasitic loads multiple infestation observed $(p<0.05)$ in those cattle having higher body weight (Table 1). However, single infestation (Ascaria) identified in lower body weight (calf). Similar observations detected for age of the tested cattle population $(p<0.05)$ in which Fasciola and Paramphistomum and Balantidium coli found at 5.50 years and Ascaria was at 0.60 years. In the table the infection rates of Ascaris were very high in the young animals starting from the age group of $<12$ months and gradually declined. In the age group $>24-36$ months and $>36$ months the infection rates were very high. Overend et al. (1984) reported same findings. The infection rate of Fasciola, Paramphistomum Stomach worm and $B$. coli were highest in the age group of $>36$ months. The increase in prevalence of these parasites with the age has been reported by Rahman and Mondol (1983); Sardar et al. (2006) and Haque (1986). In the present study it was observed that prevalence increased with age in a linear pattern and as the body weight increases with the age the prevalence increases with the body weight in the same pattern.

Table 1. Different internal parasitic infestation of cattle.

\begin{tabular}{|c|c|c|c|c|c|c|}
\hline \multirow[b]{2}{*}{ Infestation category with parasite } & \multicolumn{3}{|c|}{ Body weight (kg) } & \multicolumn{3}{|c|}{ Age (year) } \\
\hline & $\mathbf{N}$ & Mean \pm SE & $\begin{array}{l}P \\
\text { value }\end{array}$ & $\mathbf{N}$ & Mean \pm SE & $\begin{array}{l}P \\
\text { value }\end{array}$ \\
\hline Not found & 138 & $172.64 \pm 9.04^{\mathrm{a}}$ & & 138 & $3.18 \pm 0.22^{\mathrm{ab}}$ & \\
\hline Fasciola & 188 & $197.58 \pm 8.28^{\mathrm{a}}$ & & 118 & $4.38 \pm 0.23^{\mathrm{ab}}$ & \\
\hline Paramphiastomum & 52 & $173.46 \pm 13.44^{\mathrm{ab}}$ & & 52 & $3.63 \pm 0.35^{\mathrm{ab}}$ & \\
\hline Balantidium coli & 105 & $205.57 \pm 9.63^{\mathrm{a}}$ & & 105 & $3.78 \pm 0.24^{\mathrm{ab}}$ & \\
\hline Stomach worm & 45 & $178.56 \pm 13.44^{\mathrm{a}}$ & & 45 & $3.25 \pm 0.31^{\mathrm{ab}}$ & \\
\hline Eimeria & 10 & $160.00 \pm 32.96^{\mathrm{ab}}$ & & 10 & $2.98 \pm 0.60^{\mathrm{b}}$ & \\
\hline Schistoma & 8 & $191.25 \pm 41.11^{\mathrm{a}}$ & & 8 & $4.31 \pm 1.31^{\mathrm{ab}}$ & \\
\hline Ascaria & 3 & $45.00 \pm 7.64^{\mathrm{b}}$ & 0.013 & 3 & $.60 \pm 0.21^{\mathrm{c}}$ & 0.001 \\
\hline Fasciola + Paramphiastomum & 88 & $196.93 \pm 9.12^{\mathrm{a}}$ & & 88 & $4.16 \pm 0.27^{\mathrm{ab}}$ & \\
\hline Paramphiastomum + Balantidium coli & 19 & $208.95 \pm 91.48^{\mathrm{a}}$ & & 19 & $4.63 \pm 0.81^{\mathrm{ab}}$ & \\
\hline Fasciola + Balantidium coli & 50 & $202.20 \pm 10.70^{\mathrm{a}}$ & & 50 & $4.17 \pm 0.41^{\mathrm{ab}}$ & \\
\hline Fasciola + Eimeria & 9 & $168.89 \pm 37.58^{\mathrm{ab}}$ & & 9 & $3.54 \pm 1.05^{\mathrm{ab}}$ & \\
\hline Balantidium coli + Stomach worm & 10 & $179.00 \pm 32.26^{\mathrm{a}}$ & & 10 & $2.95 \pm 0.75^{\mathrm{b}}$ & \\
\hline Fasciola + Paramphiastomum + Balantidium coli & 13 & $217.69 \pm 26.17^{\mathrm{a}}$ & & 13 & $5.50 \pm 1.13^{\mathrm{a}}$ & \\
\hline Fasciola + Paramphiastomum + Eimeria & 4 & $225.00 \pm 9.57^{\mathrm{a}}$ & & 4 & $3.50 \pm 0.65^{\mathrm{ab}}$ & \\
\hline Others & 30 & $144.17 \pm 13.47^{\mathrm{ab}}$ & & 30 & $2.81 \pm 0.35^{\mathrm{b}}$ & \\
\hline
\end{tabular}

$\mathrm{N}=$ Number of observation

Different lettering within the column showing significant relationship among the groups.

Season wise prevalence rates of different parasitic infections are presented in the Table 2. In the Summer, single infestation was found higher (44\%) followed by double (32\%) and non-infestation (17\%). Similar patterns observed in Rainy, Autumn and Winter seasons of the studied feces samples. These data indicated higher percentage of single infestation in the tested samples followed by double parasitic loads. In addition, single infestation was higher in Autumn (54\%) and Winter (59\%) season while double parasitic loads found frequently in Summer (32\%) and Rainy (37\%) seasons. The infection rate of Ascaris was highest in winter. The present study correlated with the findings of the Eysker and Ogunsusi (1980) and Sardar et al. (2006). The high rate of infection in rainy season is quite reasonable. Because during this time the rainfall is abundant and there is 
abundance of intermediate hosts of Fasciola and Paramphistomum. The temperature and humidity become optimum for larval development of parasites in this season and are favorable for the migration and development of infective stage in snails.

Table 2. Intensity of parasitic infestation in different seasons.

\begin{tabular}{lllllllll}
\hline \multirow{2}{*}{ Season } & \multicolumn{2}{l}{ Not found } & \multicolumn{2}{c}{ Single infestation } & \multicolumn{2}{c}{ Double infestation } & \multicolumn{2}{c}{ Triple infestation } \\
\cline { 2 - 9 } & $\mathbf{N}$ & $\mathbf{\%}$ & $\mathbf{N}$ & $\mathbf{\%}$ & $\mathbf{N}$ & $\mathbf{\%}$ & $\mathbf{N}$ & $\mathbf{\%}$ \\
\hline Summer & 34 & 16.80 & 88 & 43.60 & 64 & 31.70 & 16 & 7.90 \\
Rainy & 35 & 18.60 & 83 & 44.10 & 67 & 35.60 & 3 & 1.60 \\
Autumn & 29 & 17.2 & 92 & 54.4 & 44 & 26.00 & 4 & 2.40 \\
Winter & 40 & 28.00 & 84 & 58.70 & 16 & 11.20 & 3 & 2.10 \\
\hline
\end{tabular}

$\mathrm{N}=$ Number of observation

The frequency of Fasciola (21\%) observed more followed by Fasciola + Paramphiastomum (13\%) and Balantidium coli (10\%) in the Summer. The frequency of Fasciola and Balantidium coli identified in similar pattern during Rainy, Autumn and Winter seasons. These data suggested that proper measure should be taken for those specific parasitic infestations in those areas from where feces samples were tested (Rahman et al., 1973). The findings were correlated with the findings of the Eysker and Ogunsusi (1980) and Sardar et al. (2006) and Hossain et al. (2012).

Table 3. Frequency of parasitic infestation in different seasons.

\begin{tabular}{|c|c|c|c|c|c|c|c|c|}
\hline \multirow{2}{*}{ Infestation of parasite } & \multicolumn{2}{|c|}{ Summer } & \multicolumn{2}{|c|}{ Rainy } & \multicolumn{2}{|c|}{ Autumn } & \multicolumn{2}{|c|}{ Winter } \\
\hline & $\mathbf{N}$ & $\%$ & $\mathbf{N}$ & $\%$ & $\mathbf{N}$ & $\%$ & $\mathbf{N}$ & $\%$ \\
\hline Not found & 34 & 16.8 & 40 & 28.0 & 29 & 17.2 & 40 & 28.0 \\
\hline Fasciola & 42 & 20.8 & 31 & 21.7 & 19 & 11.2 & 31 & 21.7 \\
\hline Paramphiastomum & 9 & 4.5 & 9 & 6.3 & 17 & 10.1 & 9 & 6.3 \\
\hline Balantidium coli & 20 & 9.9 & 29 & 20.3 & 37 & 21.9 & 29 & 20.3 \\
\hline Stomach worm & 4 & 2.0 & 10 & 7.0 & 14 & 8.3 & 10 & 7.0 \\
\hline Eimeria & 9 & 4.5 & - & - & 1 & 6 & - & - \\
\hline Schistoma & 2 & 1.0 & 2 & 1.4 & 2 & 1.2 & 2 & 1.4 \\
\hline Ascaria & 2 & 1.0 & - & - & 1 & .6 & - & - \\
\hline Fasciola + Paramphiastomum & 27 & 13.4 & 3 & 2.1 & 18 & 10.7 & 3 & 2.1 \\
\hline Paramphiastomum + Balantidium coli & 4 & 2.0 & 4 & 2.8 & 3 & 1.8 & 4 & 2.8 \\
\hline Fasciola + Balantidium coli & 15 & 7.4 & 7 & 4.9 & 13 & 7.7 & 7 & 4.9 \\
\hline Fasciola + Eimeria & 9 & 4.5 & - & - & - & - & - & - \\
\hline Balantidium coli + Stomach worm & 1 & .5 & 2 & 1.4 & 5 & 3.0 & 2 & 1.4 \\
\hline Fasciola + Paramphiastomum + Balantidium coli & 5 & 2.5 & 3 & 2.1 & 3 & 1.8 & 3 & 2.1 \\
\hline Fasciola + Paramphiastomum + Eimeria & 4 & 2.0 & - & - & - & - & - & - \\
\hline Others & 15 & 7.4 & 3 & 2.1 & 7 & 4.1 & 3 & 2.1 \\
\hline
\end{tabular}

$\mathrm{N}=$ Number of observation

In the tested feces samples of male and female $15.2 \%$ and $17.5 \%$ were found for Fasciola in both followed by Balantidium coli, respectively, $15.2 \%$ and $14.9 \%$ (Table 4). In case of double infestation of Fasciola \& Paramphiastomum and Fasciola \& Balantidium coli were $12.3 \%$ and $12.7 \%$ and $7.4 \%$ and $7.0 \%$, respectively. The findings were in line with the findings of the Eysker and Ogunsusi (1980) and Hossain et al. (2012).

Table 4. Frequency of infestation according to sex of cattle.

\begin{tabular}{llccc}
\hline \multirow{2}{*}{ Infestation of parasite } & \multicolumn{2}{c}{ Male } & \multicolumn{2}{c}{ Female } \\
\cline { 2 - 5 } & $\mathbf{N}$ & $\mathbf{\%}$ & $\mathbf{N}$ & $\mathbf{\%}$ \\
\hline Fasciola & 31 & 15.2 & 87 & 17.5 \\
Balantidium coli & 31 & 15.2 & 74 & 14.9 \\
Fasciola + Paramphiastomum & 25 & 12.3 & 63 & 12.7 \\
Fasciola + Balantidium coli & 15 & 7.4 & 35 & 7.0 \\
\hline
\end{tabular}

$\mathrm{N}=$ Number of observation 
The variation between the present study with most of the previous study of the first world countries might be due to the differences among the geographical locations, climatic conditions of the study areas, method of study, sample size, genotype of animals etc. (Soulsby 1982 and Overend et al., 1984). Baghabari is a tropical area with hot humid environment. Most of the animals here reared in scavenging or semi-scavenging rearing system. In these types of rearing system animals grazed on the fields and possibly this type of management practice plays a vital role for high rate of parasitic infection in animals. For controlling the parasites, modern anthelmintic are being used worldwide to treat and control parasitism in cattle and other animals. Blood et al. 1990 stated that a number of drugs such as albendazole, fenbendazole, mebendazole, tetramisole hydrochloride, oxyclozanide etc. effective against helminthes. These drugs are commercially available in the local market with different trade names from different producers. Experiments are carried out in Bangladesh to detect the efficacy of some commercially available anthelmintics and efficacies varied ranging from 80-100\% among them (Haque et al., 1986). But their information on their uses and effectiveness at the farmers' level are scanty (Islam et al., 1971). Most of the farmers are unaware of the extent of the loss caused by parasites in their animals. As a result animals are frequently suffered from parasitism hence malnutrition.

\section{Conclusions}

Results of this study revealed the overall prevalence of gastro-intestinal nematodes infection in cattle in Bangladesh are very high. Although a number of drugs are commercially available in the local market for the treatment against parasitism but most of the farmers are unaware and not properly treated their animals. Therefore, it is suggested that anthelmentic treatment on quarterly basis may be implemented to reduce the risk of re-infection as well as separate grazing practice can be adopted. Further studies are suggested which will help to take obligatory preventive and control measures against parasitism as well as maximize the production.

\section{Conflict of interest}

None to declare.

\section{References}

Blood DC, OM Radostits, JA Henderson, JH Arundel and CC Gay, 1990. Veterinary Medicine. 7th edn., The English Language Book Society and Bailliere Tindall.

Eysker M and RA Ogunsusi, 1980. Observation on epidemiological and clinical aspects of gastro-intestinal helminthiasis of sheep in Northern Nigeria during rainy season. Res. Vet. Sci., 28: 58-62.

Haque MA, 1986. Effects of sex, age, breed, season and system of management in the infectivity of gastrointestinal parasitism in cattle. MS thesis, Department of Medicine, Faculty of Veterinary Science, BAU, Mymensingh.

Ilyas N, MM Hossain, MJU Bhuyan and MMH Khan, 2016. Prevalence of Gastro-intestinal Nematodes Infection of Cattle in Bangladesh. AJPCT, 4: 091-097.

Islam KS, H Shaikh and KN Soliman, 1971. Occurrence of visceral Schistosomiasis of cattle and goats in East Pakistan. Proc. Pakistan Science Conference, University of Peshwar. p. 16.

Islam MN, JA Begum, YA Sarker, S Aktar and MH Sikder, 2015. Retrospective study of diseases of cattle at Adamdighi Veterinary Hospital, Bogra. Bangladesh Vet., 32: 7-12.

Kabir MHB, M Eliyas, MA Hashem, Mohiuddin and OF Miazi, 2010. Prevalence of zoonotic parasitic diseases of domestic animals in different abattoir of Comilla and Brahman Baria region in Bangladesh. Univ. J. Zool. Rajshahi Univ., 28: 21-25.

Overend D, PI Veale and JW Copeland, 1984. An epidemiological study of Trichostrongylidiasis in dairy cattle grazing in irrigated pasture. Aust. Vet. J., 61: 6-8.

Rahman MF and Z Ahmed, 1991. Final report of "Pilot project for the control of parasitic disease of animals in Bangladesh", Bangladesh Livestock Research Institute, Dhaka.

Rahman MH and MH Mondol, 1983. Helminth parasites of cattle (Bos indicus) in Bangladesh. Indian Parasitology, 7: 173-174.

Rahman MH and A Razzak, 1973. Incidence of helminth parasites infecting cattle in the Kotowali Thana of Comilla. First Bangladesh Veterinary Conference. BAU, Mymensingh. P-25.

Ross JG, RP Lee and J Armour, 1959. Haemonchosis in Nigerian Zebu Cattle: The influence of genetic factors in resistance. Vet. Rec., 71: 27-31.

Sardar SA, MA Ehsan, AKMM Anower, MM Rahman and MA Islam, 2006. Incidence of liver flukes and gastro-intestinal parasites in cattle. Bangl. J. Vet. Med., 4: 39-42. 
Sarker MAS, M Aktaruzzaman, AKMA Rahman and MS Rahman, 2013. Retrospective study of clinical diseases and disorders of cattle in Sirajganj district in Bangladesh. Bangl. J. Vet. Med., 11: 137-144.

Sarker YA, AH Miah, N Sharif, MH Himel, S Islam, RC Ray, TK Paul, MT Islam and MH Sikder, 2015. A retrospective study of common diseases at Veterinary Teaching Hospital, Bangladesh Agricultural University, Mymensingh. Bangl. J. Vet. Med., 13: 55-61.

Soulsby EJL, 1982. Helminths, Arthropods and Protozoa of Domestic Animals. 7th edn., The English Language Book Society and Bailliere Tindall. 